\title{
PROSEDUR PEMBAYARAN DANA PENSIUN PADA PT. BANK PEMBANGUNAN DAERAH BALI CABANG SINGARAJA
}

\author{
Putu Indira Astra \\ Jurusan Akuntansi Program Diploma III, \\ Universitas Pendidikan Ganesha, Singaraja \\ Indiraastra@yahoo.com
}

\begin{abstract}
Abstrak
Penelitian ini bertujuan Untuk mengetahui Prosedur Pembayaran Dana Pensiun Pada PT. Bank Pembangunan Daerah Bali Cabang Singaraja. Subjek dalam penelitian ini adalah PT. Bank Pembangunan Daerah Bali Cabang Singaraja.

Metode pengumpulan data yang digunakan dalam penelitian ini adalah Metode wawancara, dokumentasi, dan Observasi. Data yang digunakan adalah data kualitatif berupa sejarah PT. Bank Pembangunan Daerah Bali Cabang Singaraja, Struktur, Kedudukan, Tugas dan fungsi dari PT. Bank Pembangunan Daerah Bali Cabang Singaraja dan Prosedur Pembayaran Dana Pensiun pada PT. Bank Pembangunan Daerah Bali Cabang Singaraja. Selanjutnya data akan dianalisis dengan menggunakan teknik analisis deskriptif kualitatif yakni menyusun keterangan-keterangan yang bersifat uraian untuk mengetahui prosedur pembayaran dana pensiun pada PT. Bank Pembangunan Daerah Bali Cabang Singaraja.

Hasil penelitian menunjukkan bahwa prosedur pembayaran dana pensiun yang diterapkan sudah sesuai dengan standar operasional prosedur pada PT. Bank Pembangunan Daerah Bali Cabang Singaraja yaitu semuanya sudah tersusun atau terprogram dengan jelas, baik dari awal pembuatan rekening sampai pembayaran dana pensiun, dan masing-masing pos sudah melaksanakan tugasnya atau kewajibannya dengan baik sehingga para peserta dana pensiun tidak merasa bingung pada saat akan mengambil dana pensiun.
\end{abstract}

Kata kunci: prosedur, pembayaran, dana Pensiun,

This study aims to determine the Pension Fund Payment Procedure At PT. Bank Pembangunan Daerah Bali Cabang Singaraja. Subjects in this study is PT. Bank Pembangunan Daerah Bali Cabang Singaraja.

Data collection methods used in this research is the method of interview, documentation and observation. The data used is qualitative data in the form of the history of PT. Regional Development Bank Bali Singaraja Branch, structure, position, duties and functions of the PT. Regional Development Bank Bali Singaraja and Payment Procedures Branch of the Pension Fund at PT. Bank Pembangunan Daerah Bali Cabang Singaraja. Furthermore, the data will be analyzed using qualitative descriptive analysis techniques that make up the particulars are descriptions to determine the procedure for payment of pension funds in PT. Bank Pembangunan Daerah Bali Cabang Singaraja.

The results showed that the procedure for payment of pension funds that are applied are in accordance with standard operating procedures at PT. Regional Development Bank Bali branch of Singaraja that everything has been arranged or programmed with a clear, both from the inception of the account until the payment of the pension fund, and each item has been carrying out their duties or obligations so well that the pension fund participants do not feel confused at the time would take funds pension.

Keywords: procedures, payment, pension funds, 


\section{Pendahuluan}

Pekerjaan merupakan hal yang penting bagi setiap orang dimana bekerja merupakan sarana guna mendapatkan penghasilan untuk dapat memenuhi kebutuhan hidup mereka. Kebutuhan yang tercukupi merupakan suatu bentuk dari kesejahteraan yang didambakan oleh setiap orang terutama ketika memasuki hari tua dengan tenang tanpa harus memikirkan lagi urusan pekerjaan.

Pegawai Negeri Sipil (PNS) mempunyai kedudukan dan peranan yang penting serta menentukan dalam penyelenggaraan Negara/Pemerintahan. Kelancaran pelaksanaan pembangunan nasional pada pokoknya tergantung dari semangat, tekad, sikap mental, dan kedisplinan unsur aparatur negara. Mengingat pentingnya peranan Pegawai Negeri Sipil (PNS) dalam pembangunan nasional maka perlu diberikan perlindungan, pemeliharaan, serta peningkatan kesejahteraan sehingga pada gilirannya akan dapat meningkatkan produktivitas kerja.

Usaha peningkatan kesejahteraan Pegawai Negeri Sipil (PNS) dan keluarganya dilakukan melalui penyelenggaraan program Pensiun PNS.

Salah satu bank yang dipercayai oleh para pensiun sebagai juru bayar dalam pembayaran dana pensiun dari TASPEN ke peserta dana pensiun adalah PT. Bank Pembangunan Daerah Bali Cabang Singaraja. Para peserta dana pensiun yang telah mempercayai PT. Bank Pembangunan Daerah Bali Cabang Singaraja sebagai juru bayar dana pensiunannya terlebih dahulu wajib membuka rekening tabungan. Berdasarkan informasi yang penulis dapatkan dari para pensiunan, pegawai yang akan memasuki masa pensiun berkewajiban melaporkan masa jabatan yang akan berakhir ke PT. Dana Tabungan dan Asuransi Pegawai Negeri (TASPEN) dengan melampirkan SK terakhir, pas photo, kartu pegawai dan nomor membawa rekening tabungan, serta mengisi formulir pendaftaran peserta dana pensiun untuk mendapat tunjangan pensiunan. Proses pembukaan rekening tabungan di PT. Bank Pembangunan Daerah Bali Cabang Singaraja mudah dan cepat, dengan biaya administrasi yang sangat murah. Maka dari itu banyak peserta pensiunan yang mempercayakan PT. Bank Pembangunan Daerah Bali Cabang Singaraja sebagai juru bayar di dalam program dana pensiunnya.

Sesuai keputusan Menteri Negara Pendayagunaan Aparatur Negara, prosedur atau tata cara pelayanan pembayaran kepada masyarakat harus mengandung sendi-sendi kesederhanaan, kejelasan dan kepastian, keamanan dan kenyamanan, keterbukaan, efisiensi, ekonomis, keadilan yang merata serta ketepatan waktu. Dengan adanya prosedur yang jelas dan sederhana, proses pelayanan pembayaran dana pensiun dapat berjalan efektif dan efisien.

\section{Metode Penelitian}

Lokasi penelitian ini dilakukan di PT. Bank Pembangunan Daerah Bali Cabang Singaraja yang beralamat di Jln. Dewi Sartika No. 30 Singaraja dengan nomor telepon (0362) 21245 dan Nomor Fax. (0362) 23240.

Dalam penulisan laporan ini yang dijadikan subjek dari penelitian ini adalah PT. Bank Pembangunan Daerah Bali Cabang Singaraja. Dan objek penelitian ini adalah Sistem dan Prosedur Pembayaran Dana Pensiun.

Jenis data yang digunakan adalah data kualitatif. Data kualitatif adalah data yang dinyatakan dalam bentuk kata, kalimat dan gambar. Data kualitatif yang digunakan seperti sejarah PT. Bank Pembangunan Daerah Bali Cabang Singaraja, Struktur, Kedudukan, Tugas dan fungsi dari PT. Bank Pembangunan Daerah Bali Cabang Singaraja dan Prosedur Pembayaran Dana Pensiun pada PT. Bank Pembangunan Daerah Bali Cabang Singaraja.

Sumber data yang digunakan dalam penelitian ada dua yaitu data primer dan data sekunder. Data primer adalah data yang diperoleh melalui wawancara langsung. Data primer dalam penelitian ini berupa prosedur Pembayaran Dana Pensiun. Data sekunder adalah data yang diperoleh dengan memanfaatkan data yang diperoleh dari objek yang diteliti, dalam hal ini di PT. Bank Pembangunan Daerah Bali Cabang Singaraja. Data Sekunder dalam penelitian ini yaitu penjelasan tentang PT. Bank Pembangunan Daerah Bali Cabang 
Singaraja baik mengenai sejarah, struktur organisasi, kedudukan, tugas dan fungsi PT. Bank Pembangunan Daerah Bali Cabang Singaraja.

Data yang dibutuhkan dalam penelitian ini dikumpulkan dengan cara menerapkan berbagai teknik pengumpulan data, yaitu Teknik Wawancara yaitu pengumpulan data dengan cara Tanya jawab langsung dengan pegawai yang menangani langsung tentang pembayaran dana pensiun kepada para peserta pensiun. Teknik Dokumentasi yaitu pengumpulan data yang dilakukan melalui catatan-catatan atau dokumen yang ada di PT. Bank Pembangunan Daerah Bali Cabang Singaraja dan Teknik Observasi yaitu pengumpulan data yang langsung dilakukan dengan pengamatan dan pencatatan secara langsung yang ada di PT. Bank Pembangunan Daerah Bali Cabang Singaraja berupa sejarah, struktur organisasi, kedudukan, tugas dn fungsi beserta prosedur pembayaran dana pensiun pada PT. Bank Pembangunan Daerah Bali Cabang Singaraja.

Dalam penelitian ini analisis data yang digunakan adalah teknik analisis deskriptif kualitatif yaitu teknik analisis yang tidak berupa angka-angka akan tetapi berupa keteranganketerangan yang bersifat uraian dan nantinya akan disusun secara sistematis untuk mengetahui prosedur pembayaran dana pensiun pada PT. Bank Pembangunan Daerah Bali Cabang Singaraja agar dapat ditarik kesimpulan yang nantinya dapat dipertanggung jawabkan dan bermanfaat bagi para pembacanya.

\section{Hasil Penelitian}

\section{Prosedur Pembayaran Dana Pensiun Pada PT. Bank Pembangunan Daerah Bali Cabang Singaraja.}

Jaminan kesejahteraan yang dikemas dalam manfaat pensiun diberikan pada karyawan dan keluarganya secara berkala sesuai dengan cara yang ditetapkan dalam Peraturan Dana Pensiun, yaitu Undang-Undang Nomor 11 tahun 1992. Undang-undang tersebut didukung PP Nomor 761992 tentang Dana Pensiun Lembaga Keuangan. Perangkat-perangkat peraturan tersebut diundangkan dengan maksud untuk mendukung terselenggaranya pengelolaan dana pensiun yang dapat memberikan manfaat yang optimal bagi pesertanya.

Di Indonesia, melalui Undng-Undang Nomor 7 Tahun 1983 tentang Pajak Penghasilan dan Keputusan Menteri Keuangan Nomor 250/KMK.00111985 tanggal 6 Maret 1985 telah memberikan perlakuan khusus kepada dana pensiun, sebagai salah satu upaya dalam mengembangkan minat swasta untuk penyelenggaraan program pensiun guna memberikan kesejahteraan dan jaminan hidup hari tua kepada karyawannya. Selain itu diharapkan bahwa dana pensiun, sebagai salah satu alternatif pembiayaan, akan ikut memarakkan sektor keuangan dalam upaya mendorong kehidupan ekonomi dan pembangunan yang lebih dinamis di Indonesia.

Dalam hal ini, PT TASPEN akan bekerja sama dengan badan usaha atau lembaga keuangan yang dipercaya oleh para peserta dana pensiun sebagai juru bayar didalam pembayaran dana pensiun. Salah satu bank yang dipercayai oleh para pensiun sebagai juru bayar dalam pembayaran dana pensiun dari TASPEN ke peserta dana pensiun adalah PT. Bank Pembangunan Daerah Bali Cabang Singaraja.

Sejalan dengan perkembangan perbankan, semakin banyak para peserta pensiunan yang menggunakan jasa bank. Begitu pula PT. Bank Pembangunan Daerah Bali Cabang Singaraja yang bergerak dalam bidang perbankan yang menghimpun dana dari pihak ketiga dan menyalurkannya kembali melalui bentuk kredit dan jasa-jasa lainnya dalam lalu lintas pembayaran dan peredaran uang, memiliki cukup banyak nasabah para pensiunan didalam pelayanan untuk pembayaran dana pensiun. Pelayanan sebagai juru bayar dalam program dana program dana pensiun di PT. Bank Pembangunan Daerah Bali Cabang Singaraja mengacu pada prinsip-prinsip pelayanan prima seiring dengan visi dan misi pada PT. Bank Pembangunan Daerah Bali Cabang Singaraja.

Prosedur pembayaran dana pensiun diawali dengan pembuatan rekening tabungan baru kemudian para pegawai yang akan memasuki masa pensiun mendaftarkan diri ke PT. TASPEN setelah itu para pensiunan dapat mengambil dana pensiunnya pada PT. Bank Pembangunan Daerah Bali Cabang Singaraja. Dalam pengambilan dana pensiun ada 
perbedaan antara tahun genap dan tahun ganjil. Saat pengambilan dana pensiun pada tahun genap para nasabah pensiunan hanya perlu menyerahkan formulir penarikan, dan buku tabungan kepada teller dan pada tahun ganjil para peserta dana pensiun harus mengisi formulir Surat Pengesahan Tanda Bukti Diri (SPTB) dengan tujuan untuk mengetahui jumlah tanggungan yang masih ditanggung oleh para nasabah pensiunan dan untuk mengetahui bahwa penerima pensiunan masih hidup atau sudah meninggal.

Mulai tanggal satu para nasabah pensiunan dapat mengambil dana pensiun. Nasabah wajib mengambil dana pensiun sendiri, kecuali nasabah berhalangan dengan bukti yang kuat. Nasabah dapat menunjuk seseorang yang membawa surat kuasa bermaterai 6000 rupiah beserta stempel dari lurah setempat. Lurah setempat dan penerima kuasa bertandatangan dalam surat kuasa.

Dalam proses pembayaran dana pensiun apabila yang menjadi pemegang hak dana pensiun meninggal, pemegang hak waris wajib melaporkan bahwa pemegang hak dana pensiun sudah meninggal dengan memberikan bukti-bukti bahwa dia memang benar pemegang hak waris serta harus mengisi formulir. Atas dasar inilah untuk selanjutnya pemegang hak waris bisa mengambil dana pensiun.

\section{Pembahasan}

\section{Prosedur Pembayaran Dana Pensiun Pada PT. Bank Pembangunan Daerah Bali} Cabang Singaraja.

PT. Bank Pembangunan Daerah Bali Cabang Singaraja. dalam menjalankan Prosedur Pembayaran Dana Pensiun memegang prinsip kehati-hatian agar nantinya tidak menimbulkan masalah yang dapat merugikan pihak Bank terutama ketika melakukan Pembayaran Dana Pensiun.

Dalam implementasinya, Prosedur Pembayaran Dana Pensiun pada PT. Bank Pembangunan Daerah Bali Cabang Singaraja sudah sesuai dengan Standard Operating Procedure (SOP), itu semua dapat dilihat dari proses dan tahapan-tahapan Pembayaran Dana Pensiun sudah diikuti oleh nasabah dengan baik didukung dengan dokumen-dokumen yang dapat mendukung proses pembayaran dana pensiun, serta dipatuhinya tahapan pelaksanaan prosedur pembayaran dana pensiun oleh PT. Bank Pembangunan Daerah Bali Cabang Singaraja sesuai dengan tahapan yang dibuat oleh PT. Bank Pembangunan Daerah Bali Cabang Singaraja itu sendiri. Selain itu, pelayanan pembayaran dana pensiun yang diberikan kepada nasabah oleh PT. Bank Pembangunan Daerah Bali Cabang Singaraja sudah optimal terlihat dari respon positif nasabah pensiunan dengan lancarnya proses pembayaran dana pensiun.

Prosedur pembayaran pensiun PT. Bank Pembangunan Daerah Bali Cabang Singaraja diawali dengan pembukaan rekening tabungan PT. Bank Pembangunan Daerah Bali Cabang Singaraja. Jika calon peserta penerima dana pensiun memilih PT. Bank Pembangunan Daerah Bali Cabang Singaraja sebagai tempat pengambilan pensiunan maka calon nasabah pensiunan selanjutnya akan mengurus tabungan di PT. Bank Pembangunan Daerah Bali Cabang Singaraja. Pembukaan rekening tabungan ini dilakukan pada bagian Customer Service dengan menyerahkan fotocopy (Kartu Tanda Penduduk) KTP atau SIM 2 (dua) rangkap dan fotocopy Kartu (Nomor Pokok Wajib Pajak) NPWP 2 (dua) rangkap. Selanjutnya pada bagian Customer Service calon nasabah akan diminta untuk mengisi formulir aplikasi pembukaan rekening tabungan, mengisi tanda tangan pada buku tabungan dan membayar biaya administrasi untuk setoran awal sebesar Rp 100.000. Bagian Customer Service akan menyerahkan buku tabungan dan biaya administrasi tersebut ke teller untuk melakukan pencetakan nomor tabungan, nama, nomor identitas dan alamat pada buku tabungan. Setelah itu buku tabungan diberikan kepada nasabah yang bersangkutan.

Setelah calon peserta penerima dana pensiun memiliki rekening tabungan, calon peserta dana pensiun kemudian mendaftarkan diri ke PT. TASPEN untuk menjadi peserta penerima dana pensiun dengan persyaratan seperti SK terakhir, pas foto, kartu pegawai dan nomor rekening tabungan serta mengisi formulir pendaftaran peserta dana pensiun. Formulir tersebut akan menjadi dasar pembuatan DAPEM (Daftar Pembayaran Pensiun) yang 
kemudian akan disetorkan ke pada PT. Bank Pembangunan Daerah Bali Cabang Singaraja sebagai tempat pembayaran dana pensiun.

Selanjutnya prosedur pembayaran dana pensiun ke nasabah diawali dengan nasabah pensiun mengisi formulir penarikan tabungan. Nasabah mengisi kolom tanggal, jumlah rupiah yang akan ditarik, nama nomor rekening dan tanda tangan. Nasabah pensiun menyiapkan buku tabungan berikut KTP (kartu tanda penduduk) dan formulir penarikan yang telah diisi. Nasabah menuju teller dengan sistem antri. Teller memeriksa kelengkapan pengisian formulir penarikan tabungan. Setelah memeriksa formulir penarikan tabungan, teller melakukan proses pembayaran dengan menerima, memeriksa dan mencocokan buku tabungan uang pensiun, KTP dan formulir penarikan dari nasabah pensiun. Teller mencocokan data yang ada pada DAPEM (Daftar Pembayaran Pensiun) dengan data tabungan uang pensiun dan KTP yang bersangkutan. Setelah cocok, teller mencetak buku tabungan yang bersangkutan dan menyerahkan uang bersama-sama dengan formulir penarikan kepada nasabah untuk ditandatangani sebagai tanda terima. Setelah itu teller menyerahkan buku tabungan dan KTP kepada nasabah.

Dalam pengambilan dana pensiun ada perbedaan antara tahun genap dan tahun ganjil. Saat pengambilan dana pensiun pada tahun genap para nasabah pensiunan hanya perlu menyerahkan formulir penarikan, KTP, dan buku tabungan kepada teller setelah itu teller bisa menyerahkan dana pensiun kepada nasabah pensiun. Sedangkan pada tahun ganjil para peserta dana pensiun selain menyerahkan formulir penarikan, KTP, dan buku tabungan kepada teller nasabah pensiun harus mengisi formulir Surat Pengesahan Tanda Bukti Diri (SPTB) dan disahkan oleh lurah, kepala desa atau camat setempat dengan tujuan untuk mengetahui jumlah tanggungan yang masih ditanggung oleh para nasabah pensiunan serta untuk mengetahui bahwa penerima pensiunan masih hidup atau sudah meninggal. setelah itu teller bisa menyerahkan dana pensiun kepada nasabah pensiun

Mulai tanggal satu para nasabah pensiunan dapat mengambil dana pensiun. Nasabah wajib mengambil dana pensiun sendiri, kecuali nasabah berhalangan dengan bukti yang kuat. Nasabah dapat menunjuk seseorang yang membawa surat kuasa bermaterai 6000 rupiah beserta stempel dari lurah setempat. Lurah setempat dan penerima kuasa bertandatangan dalam surat kuasa. Dalam proses pembayaran dana pensiun apabila yang menjadi pemegang hak dana pensiun meninggal, dana pensiun masih tetap bisa dibayarkan kepada pemegang hak waris yang sebelumnya sudah terdaftar dalam formulir yang diisi oleh pihak pertama peserta dana pensiun. Pemegang hak waris wajib melaporkan bahwa pemegang hak dana pensiun sudah meninggal dengan memberikan bukti-bukti bahwa dia memang benar pemegang hak waris. Kemudian pemegang hak waris harus mengganti kepemilikan buku tabungan pada bagian customer service dari atas nama pihak pertama menjadi atas nama pemegang hak waris. Untuk selanjutnya dana pensiun bisa dibayarkan kepada pemegang hak waris.

\section{Penutup}

\subsection{Simpulan}

Berdasarkan pada pembahasan sebelumnya, mengenai prosedur pembayaran dana pensiun pada PT. Bank Pembangunan Daerah Bali Cabang Singaraja. Maka dapat ditarik kesimpulan yaitu prosedur pembayaran dana pensiun yang diterapkan sudah sesuai dengan standar operasional prosedur pada PT. Bank Pembangunan Daerah Bali Cabang Singaraja yaitu semuanya sudah tersusun atau terprogram dengan jelas, baik dari awal pembuatan rekening sampai pembayaran dana pensiun, dan masing-masing pos sudah melaksanakan tugasnya atau kewajibannya dengan baik sehingga para peserta dana pensiun tidak merasa bingung pada saat akan mengambil dana pensiun.

Prosedur pembayaran dana pensiun diawali dengan pembuatan rekening tabungan baru kemudian para pegawai yang akan memasuki masa pensiun mendaftarkan diri ke PT. TASPEN setelah itu para pensiunan dapat mengambil dana pensiunnya pada PT. Bank Pembangunan Daerah Bali Cabang Singaraja. Dalam pengambilan dana pensiun ada perbedaan antara tahun genap dan tahun ganjil. Saat pengambilan dana pensiun pada tahun genap para nasabah pensiunan hanya perlu menyerahkan formulir penarikan, dan 
buku tabungan kepada teller dan pada tahun ganjil para peserta dana pensiun harus mengisi formulir Surat Pengesahan Tanda Bukti Diri (SPTB).

\subsection{Saran}

Berdasarkan kesimpulan yang telah dikemukakan di atas, maka penulis dapat memberikan saran-saran yang khususnya mengenai prosedur pembayaran dana pensiun pada PT. Bank Pembangunan Daerah Bali Cabang Singaraja.

Kenyamanan dan kemudahan dalam prosedur pembayaran sangat diperlukan untuk menciptakan prosedur pembayaran yang baik, sehingga akan menarik lebih banyak nasabah untuk mempercayakan PT. Bank Pembangunan Daerah Bali Cabang Singaraja sebagai tempat pengambilan dana pensiunannya dan pendapatan juga akan meningkat. Selain itu juga bisa digunakan sebagai promosi untuk menarik para peserta pensiunan agar mencari kredit pada PT. Bank Pembangunan Daerah Bali Cabang Singaraja.

Dalam melaksanakan tugas-tugas dan tanggung jawab sesuai dengan struktur organisasi diperlukan kedisiplinan agar tidak terjadinya penyelewengan atau kesalahan-kesalahan saat melakukan pembayaran dana pensiun kepada nasabah pensiun.

\section{DAFTAR PUSTAKA}

Baridwan, Z. 2002. Sistem Akuntansi Penyusutan Prosedur dan Metode. Edisi Kelima. Yogyakarta: BPFE

Ikatan Akuntasi Indonesia. 2002. Standar Akuntansi Keuangan. Jakarta: Salemba Empat.

Iswardono. 1984. Uang dan Bank. Edisi Kedua, Yogyakarta: BPFE.

Kasmir. 2002. Dasar-Dasar Perbankan. Jakarta: PT RajaGrafindo Persada.

-----. 2010. Bank dan Lembaga Keuangan Lainnya. Jakarta: Rajawali Pers

Malayu S.P. Hasibuan, 2006. Dasar-Dasar Perbankan. Jakarta: PT Bumi Aksara.

Mulyadi. 2001. Sistem Akuntansi. Edisi Ketiga, Jakarta: Salemba Empat

Triandaru, Sigit dan budisantoso, Totok. 2007. Bank dan Lembaga Keuangan Lain. Jakarta: Salemba Empat.

Wahab, Zulaini, 2005. Segi Hukum Dana Pensiun. Jakarta: PT. Raja Grafindo Persada.

-----. 2001. Dana Pensiun dan Jaminan Sosial Tenaga Kerja di Indonesia. Bandung: PT. Citra Aditya Bakti. 